\title{
Payload Based Internet Worm Disclosure using Neural Network
}

\author{
R.Velvizhi, D.Vimala, I.Mary Linda
}

\begin{abstract}
With the capacity of contaminating a huge number of hosts, worms speak to a noteworthy danger to the Internet. The identification against Internet worms is generally an open issue. Web worms represent a genuine danger to PC security. Conventional methodologies utilizing marks to identify worms posture little risk to the zero day assaults. The focal point of this exploration is moving from utilizing mark examples to distinguishing the vindictive conduct showed by the Internet worms. This paper displays an original thought of separating stream level highlights that can distinguish worms from clean projects utilizing information mining method, for example, neural system classifier. Our approach demonstrated $97.90 \%$ recognition rate on Internet worms whose information was not utilized as a part of the model building process
\end{abstract}

Index Terms:Network,Mining,Framework

\section{INTRODUCTION}

As PC and correspondence systems wind up common, the Internet has been a front line for aggressors and safeguards. A standout amongst the most effective weapons for aggressors is the Internet worm. In particular, a worm assaults powerless PC frameworks and utilizes self-spreading strategies to surge the Internet quickly. Subsequently, worms, for example, Code Red, Slammer, and Witty, have tainted a huge number of hosts and turn into a huge risk to organize security and administration. Additionally, the assaulting strategies produced by worms' planners have turned out to be progressively advanced, which postures significant difficulties to safeguards. [1],[3],[5]

The Internet is tenaciously debilitated by numerous kinds of assaults, for example, infections, and worms. A worm is a self-proliferating program that taints different hosts in light of a known helplessness in arrange has. Interestingly, an infection is a bit of code appended to another executable program, which requires human activity to spread. A noteworthy test in systems administration is the manner by which to recognize new worms and infections in the

Revised Manuscript Received on July 22, 2019.

R.Velvizhi,,Department of Computer Science and Engineering, Bharath Institute of Higher education and research, Chennai, India

D.Vimala ,Department of Computer Science and Engineering, Bharath Institute of Higher education and research, Chennai, India

I.MaryLinda,Department of Computer Science and Engineering, Bharath Institute of Higher education and research, Chennai, India beginning times of spread in a computationally effective way. Amid the previous 20 years, a large number of various worms have been produced. Some of these worms have made tremendous interruption worldwide systems. From the main worm that was discharged in 1988 (the Morris worm), the territory of Internet worm discovery has been a huge research issue. Keeping in mind the end goal to comprehend the worm risk, it is important to comprehend the different sorts of worms, payloads, and assailants. [2 ],[ 4],[6]

A system worm is characterized as a procedure that can cause a (potentially developed) duplicate of it to execute on a remote computational machine. Worms ordinarily self proliferate crosswise over systems by misusing security or arrangement blemishes in generally utilized system administrations. Worms are not quite the same as Viruses in that Viruses piggy-back on records and in this way require client activity to empower their engendering. Along these lines, infections engender at a slower rate than worms.

Whatever remains of the paper is composed as takes after. Segment 2 talks about PC worm conduct. Segment 3 examines different worm location procedures, showing the worm qualities that they use for the identification and furthermore calls attention to their inadequacies. At long last Section 4 condenses the hole that exists in the worm location space. [7],[9],[11]

\section{RELATED WORKS}

Web worms taint the system through unlawful movement stream. Checking and recognizing the noxious movement conduct gives better and speedier correspondence. As opposed to payload Inspection, activity stream observing identifies the system movement and adventures the web worms unlawful movement. Different strategies proposed for Internet worm discovery are recorded underneath: [8],[ 10] ,[12]

This method is speedier and stealthier than the irregular filtering worm. In this paper creator additionally depicted two guard instrument, they are contaminated host expulsion and dynamic presented a novel technique for identifying the system based worm. It initially creates the marks naturally by Semantics Aware measurable calculation. This is utilized to evacuate the non-basic bytes, which is joined with a shrouded Markov model to naturally produce worm marks.

In another information mining approach, utilized three distinct kinds of highlights and an assortment of classifiers to distinguish noxious projects. Their essential dataset contained 3265 malevolent and 1001 clean projects. They connected RIPPER (a run based framework) to the DLL 
dataset. Strings information was utilized to fit a Naive Bayes classifier while n-grams were utilized to prepare a Multi-Naive Bayes classifier with a voting system. No n-gram decrease calculation was accounted for to be utilized. Rather informational collection dividing was utilized and 6 Naive-Bayes classifiers were prepared on each parcel of the information. They utilized distinctive highlights to fabricated diverse classifiers that don't represent a reasonable correlation among the classifiers. Guileless Bayes utilizing strings gave the best precision in their model.

Here the creator executed the progressive cross breed against worm. This approach was mix of dynamic and uninvolved against worm. The work done by the dynamic hostile to worm was identifying the helpless host on the system and patches them up. Listening process was taken care of by uninvolved hostile to worm, that it assaults the worm from the host in the wake of fixing it for the procedure. Proposed the way to deal with dissect the web worm disease family tree and it is named as worm tree. Through numerical investigation, catches the key attributes of the web worm identification and applying it for bot discovery. Implemented an approach in light of time deferral to lessen the system worm and furthermore diminish the financial misfortune rate. From the above related works, distinctive strategies have been proposed to identify the Internet worms tainting the system. From the perceptions, it is discovered that they identify through observing payload and activity mischievous activities. Payload discovery needs identification of worms when they are scrambled. Checking activity conduct distinguishes simply after their spread. To conquer the above restrictions, the proposed approach distinguishes the Internet worms by observing the activity stream data.

\section{RECOGNITION SYSTEM}

The proposed approach discovers the vindictive web worm stream movement payload in view of the attributes of system stream payload utilizing neural system arrangement calculation. To order the Internet worms, TCP and UDP streams are inspected, they are part into time windows and credited vector is extricated. In view of the trait vectors pernicious and non-noxious activity is identified and grouped. Figure 1 underneath demonstrates the entire procedure of identifying Internet worms through their activity streams. [38],[40]

\section{A. Flow Traffic}

System activity alludes to the measure of information moving over a system at a given purpose of time. System information is generally epitomized in arrange parcels, which give the heap in the system. System activity is the primary part for arrange movement estimation, organize activity control and recreation. The best possible association of system activity helps in guaranteeing the nature of administration in a given system. System activity is otherwise called information movement.

Streams offer a totalled perspective of system movement, by giving an account of the measure of parcels and bytes traded over the system. In this manner, streams definitely decrease the measure of information to be broke down. A stream is characterized as an arrangement of IP parcels passing a perception point in the system amid a specific time interim. All bundles having a place with a specific stream have an arrangement of basic properties. [13], [15], [17]

A stream can be characterized utilizing the accompanying parameters (Source IP Address, Destination IP Address, Source Port, Destination Port, Protocol)

\section{B. Feature Extraction}

The informational index contains three sub informational index, which are the entire informational index, $10 \%$ informational index and the test set with redress names named correct.gz. Uncommonly, we test $1 \%$ and $2 \%$ informational collection from the $10 \%$ KDD CPU99 informational index separately in our analyses, which contains 49402 and 98804 examples in comparing. There are 41 includes in each example as appeared in table 1. The assault can mostly partitioned into the accompanying four classifications.

(1) DoSspeaks to dissent of administration assault. The assailants make the memory of the PC excessively occupied and can't deal with honest to goodness demands or decline to real client's entrance to the machine. [14],[16], [18]

(2) U2R speaks to illicit access to the neighborhood super user002E the aggressors get to the root authorizations utilizing a proviso through a client without consents or lower authorizations, at that point login and make illegal[19],[21],[23]

\section{Normalization}

Amid preparing of the neural system, higher esteemed info factors may have a tendency to smother the impact of littler ones. Additionally, if the crude information is straightforwardly connected to the system, there is a danger of the reproduced neurons achieving the soaked conditions. On the off chance that the neurons get immersed, at that point the adjustments in the info esteem will create a little change or no adjustment in the yield esteem. This influences the system preparing all things considered. To limit the impacts of extents among contributions and in addition to forestall immersion of the neuron actuation work, the info information is standardized before being exhibited to the neural system. One approach to standardize an element $\mathrm{x}$ is utilizing min-max standardization. [20],[ 22], [24]

\section{Feature Selection}

Highlight determination and positioning are extremely pivotal for worm identification. Highlight choice is the way toward getting the score for every potential component and afterward acquiring the incredible ' $k$ ' highlights. Scoring is finished by tallying the recurrence of a component in preparing positive and negative class tests independently and afterward acquiring an element of both. There are numerous highlights that must be checked for worm identification out of which certain highlights will be helpful and others might be futile. The expulsion of futile highlights improves the precision and reductions the calculation time in this way accomplishing higher execution. The chi-square element determination metric is utilized as a part of our exploration. [25],[27],[29] 


\section{E. Neural Network Classifier}

A neural system comprises of units (neurons), organized in layers, which change over an info vector into some yield. Every unit takes an information, applies a (frequently nonlinear) capacity to it and afterward passes the yield on to the following layer. By and large the systems are characterized to be sustain forward: a unit bolsters its yield to every one of the units on the following layer, yet there is no criticism to the past layer. Weightings are connected to the signs going starting with one unit then onto the next, and it is these weightings which are tuned in the preparation stage to adjust a neural system to the specific issue close by. This is the learning stage. [26],[28],[30]

The Multilayer encourage forward neural systems are fitting for taking care of issues where all the data can be exhibited to the neural system without a moment's delay. In the preparation stage, a preparation set is displayed as contribution to the neural system which iteratively changes organize weights and inclinations keeping in mind the end goal to create a yield that matches, inside a specific level of exactness, a formerly known outcome. In the testing stage, another information is introduced to the system and an outcome is acquired in view of the system parameters that were figured amid the preparation stage. In this work, the system is prepared with back proliferation learning calculation, which is a proper learning calculation for preparing multilayer sustainforward systems for vector order. The info layer has 6 neurons comparing to the dimensionality of the information vectors, and the yield layer has two neurons. The quantity of neurons in the shrouded layer is observationally chosen with the end goal that the execution work, which is the mean square mistake for encourage forward neural system is limited[31],[33],[35]

\section{TRIAL RESULTS AND DISCUSSIONS}

Every one of the examinations are directed utilizing NSL-KDD dataset and CAIDA dataset that has 60438 preparing occasions, 22544 cases for testing with select most unmistakable 15 characteristics and irregular timberland order to manufacture an effective web worm discovery framework. We have assessed our classifier with different assessment measures, for example, exactness, F-measure and false positive rate. [32],[34],[36]

\section{CONCLUSION}

In this paper we exhibited an information mining structure to distinguish Internet worms. The essential component utilized for the procedure was the stream level payload highlights from organize stream activity has been utilized as a part of the classifier. We utilized the stream highlights normal to the two worms and clean projects to evacuate any predispositions caused by the highlights that have every one of their events in a single class as it were. We demonstrated $97.90 \%$ recognition rate with a $0.057 \%$ false positive rate. [37],[39],[41]

\section{REFERENCES}

[1] Kumarave A., Rangarajan K.,Algorithm for automaton specification for exploring dynamic labyrinths,Indian Journal of Science and Technology,V-6,I-SUPPL5,PP-4554-4559,Y-2013

[2] P. Kavitha, S. Prabakaran "A Novel Hybrid Segmentation Method with Particle Swarm Optimization and Fuzzy C-Mean Based On Partitioning the Image for Detecting Lung Cancer" International Journal of Engineering and Advanced Technology (IJEAT) ISSN: 2249-8958, Volume-8 Issue-5, June 2019

[3] Kumaravel A., Meetei O.N.,An application of non-uniform cellular automata for efficient cryptography,2013 IEEE Conference on Information and Communication Technologies, ICT 2013,V-,I-,PP-1200-1205,Y-2013

[4] Kumarave A., Rangarajan K.,Routing alogrithm over semi-regular tessellations,2013 IEEE Conference on Information and Communication Technologies, ICT 2013,V-,I-,PP-1180-1184,Y-2013

[5] P. Kavitha, S. Prabakaran "Designing a Feature Vector for Statistical Texture Analysis of Brain Tumor" International Journal of Engineering and Advanced Technology (IJEAT) ISSN: 2249-8958, Volume-8 Issue-5, June 2019

[6] Dutta P., Kumaravel A.,A novel approach to trust based identification of leaders in social networks, Indian Journal of Science and Technology,V-9,I-10,PP--,Y-2016

[7] Kumaravel A., Dutta P.,Application of Pca for context selection for collaborative filtering,Middle - East Journal of Scientific Research,V-20,I-1,PP-88-93,Y-2014

[8] Kumaravel A., Rangarajan K.,Constructing an automaton for exploring dynamic labyrinths,2012 International Conference on Radar, Communication and Computing, ICRCC 2012,V-,I-,PP-161-165,Y-2012

[9] P. Kavitha, S. Prabakaran "Adaptive Bilateral Filter for Multi-Resolution in Brain Tumor Recognition" International Journal of Innovative Technology and Exploring Engineering (IJTTEE) ISSN: 2278-3075, Volume-8 Issue-8 June, 2019

[10] Kumaravel A.,Comparison of two multi-classification approaches for detecting network attacks,World Applied Sciences Journal,V-27,I-11,PP-1461-1465,Y-2013

[11] Tariq J., Kumaravel A.,Construction of cellular automata over hexagonal and triangular tessellations for path planning of multi-robots,2016 IEEE International Conference on Computational Intelligence and Computing Research, ICCIC 2016,V-,I-,PP--,Y-2017

[12] Sudha M., Kumaravel A.,Analysis and measurement of wave guides using poisson method,Indonesian Journal of Electrical Engineering and Computer Science,V-8,I-2,PP-546-548,Y-2017

[13] Ayyappan G., Nalini C., Kumaravel A.,Various approaches of knowledge transfer in academic social network, International Journal of Engineering and Technology,V-,I-,PP-2791-2794,Y-2017

[14] Kaliyamurthie, K.P., Sivaraman, K., Ramesh, S. Imposing patient data privacy in wireless medical sensor networks through homomorphic cryptosystems 2016, Journal of Chemical and Pharmaceutical Sciences 92.

[15] Kaliyamurthie, K.P., Balasubramanian, P.C. An approach to multi secure to historical malformed documents using integer ripple transfiguration 2016 Journal of Chemical and Pharmaceutical Sciences 92 .

[16] A.Sangeetha,C.Nalini,"Semantic Ranking based on keywords extractions in the web", International Journal of Engineering \& Technology, 7 (2.6) (2018) 290-292

[17] S.V.GayathiriDevi,C.Nalini,N.Kumar,"An efficient software verification using multi-layered software verification tool "International Journal of Engineering \& Technology, 7(2.21)2018 454-457

[18] C.Nalini,ShwtambariKharabe,"A Comparative Study On Different Techniques Used For Finger - Vein Authentication”, International Journal Of Pure And Applied Mathematics, Volume 116 No. 82017 , 327-333, Issn: 1314-3395

[19] M.S. Vivekanandan and Dr. C. Rajabhushanam, "Enabling Privacy Protection and Content Assurance in Geo-Social Networks", International Journal of Innovative Research in Management, Engineering and Technology, Vol 3, Issue 4, pp. 49-55, April 2018.

[20] Dr. C. Rajabhushanam, V. Karthik, and G. Vivek, "Elasticity in Cloud Computing", International Journal of Innovative Research in Management, Engineering and Technology, Vol 3, Issue 4, pp. 104-111, April 2018.

[21] K. Rangaswamy and Dr. C. Rajabhushanamc, "CCN-Based Congestion Control

Mechanism In Dynamic Networks", International 


\section{Payload Based Internet Worm Disclosure using Neural Network}

Journal of Innovative Research in Management, Engineering and Technology, Vol 3, Issue 4, pp. 117-119, April 2018.

[22] Kavitha, R., Nedunchelian, R., "Domain-specific Search engine optimization using healthcare ontology and a neural network backpropagation approach", 2017, Research Journal of Biotechnology, Special Issue 2:157-166

[23] Kavitha, G., Kavitha, R., "An analysis to improve throughput of high-power hubs in mobile ad hoc network" , 2016, Journal of Chemical and Pharmaceutical Sciences, Vol-9, Issue-2: 361-363

[24] Kavitha, G., Kavitha, R., "Dipping interference to supplement throughput in MANET" , 2016, Journal of Chemical and Pharmaceutical Sciences, Vol-9, Issue-2: 357-360

[25] Michael, G., Chandrasekar, A.,'Leader election based malicious detection and response system in MANET using mechanism design approach", Journal of Chemical and Pharmaceutical Sciences(JCPS) Volume 9 Issue 2, April - June 2016

[26] Michael, G., Chandrasekar, A.,"Modeling of detection of camouflaging worm using epidemic dynamic model and power spectral density", Journal of Chemical and Pharmaceutical Sciences(JCPS) Volume 9 Issue 2, April - June 2016.

[27] Pothumani, S., Sriram, M., Sridhar, J., Arul Selvan, G., Secure mobile agents communication on intranet,Journal of Chemical and Pharmaceutical Sciences, volume 9, Issue 3, Pg No S32-S35, 2016

[28] Pothumani, S., Sriram, M., Sridhar , Various schemes for database encryption-a survey, Journal of Chemical and Pharmaceutical Sciences, volume 9, Issue 3, Pg NoS103-S106, 2016

[29] Pothumani, S., Sriram, M., Sridhar, A novel economic framework for cloud and grid computing, Journal of Chemical and Pharmaceutical Sciences, volume 9, Issue 3, Pg No S29-S31, 2016

[30] Priya, N., Sridhar, J., Sriram, M. "Ecommerce Transaction Security Challenges and Prevention Methods- New Approach” 2016 ,Journal of Chemical and Pharmaceutical Sciences, JCPS Volume 9 Issue 3.page no:S66-S68

[31] Priya, N.,Sridhar,J.,Sriram, M."Vehicular cloud computing security issues and solutions" Journal of Chemical and Pharmaceutical Sciences(JCPS) Volume 9 Issue 2, April - June 2016

[32] Priya, N., Sridhar, J., Sriram, M. "Mobile large data storage security in cloud computing environment-a new approach" JCPS Volume 9 Issue 2. April - June 2016

[33] Anuradha.C, Khanna.V, "Improving network performance and security in WSN using decentralized hypothesis testing "Journal of Chemical and Pharmaceutical Sciences(JCPS) Volume 9 Issue 2, April - June 2016

[34] Anuradha.C, Khanna.V, "A novel gsm based control for e-devices" Journal of Chemical and Pharmaceutical Sciences(JCPS) Volume 9 Issue 2, April - June 2016.

[35] Anuradha.C, Khanna.V, "Secured privacy preserving sharing and data integration in mobile web environments " Journal of Chemical and Pharmaceutical Sciences(JCPS) Volume 9 Issue 2, April - June 2016.

[36] Sundarraj, B., Kaliyamurthie, K.P. Social network analysis for decisive the ultimate classification from the ensemble to boost accuracy rates 2016 International Journal of Pharmacy and Technology 8

[37] Sundarraj, B., Kaliyamurthie, K.P. A content-based spam filtering approach victimisation artificial neural networks 2016 International Journal of Pharmacy and Technology 83.

[38] Sundarraj, B., Kaliyamurthie, K.P. Remote sensing imaging for satellite image segmentation 2016 International Journal of Pharmacy and Technology 83 .

[39] Sivaraman, K., Senthil, M. Intuitive driver proxy control using artificial intelligence 2016 International Journal of Pharmacy and Technology 84

[40] Sivaraman, K., Kaliyamurthie, K.P. Cloud computing in mobile technology 2016 Journal of Chemical and Pharmaceutical Sciences 92.

[41] Sivaraman, K., Khanna, V. Implementation of an extension for browser to detect vulnerable elements on web pages and avoid click jacking 2016 Journal of Chemical and Pharmaceutical Sciences 92

\section{AUTHORS PROFILE}

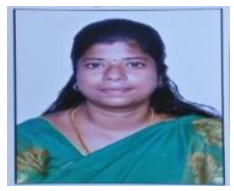

R.Velvizhi, Assistant Professor, Department of Computer Science \& Engineering, Bharath Institute of Higher Education and Research, Chennai, India

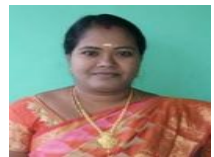

D.Vimala, Assistant Professor, Department of Computer Science \& Engineering, Bharath Institute of Higher Education and Research, Chennai, India

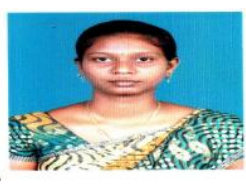

I.Mary Linda, Assistant Professor, Department of Computer Science \& Engineering, Bharath Instituteof Higher Education and Research, Chennai, India 